\title{
Effects of variable effort expenditure on subsequent preference for the reinforcer'
}

ROBERT M. CRISTAL

YESHIVA UNIVERSITY

Four groups of male albino rats received the same number of reinforcements of $0.1 c c$ maltose solution in a Skinner box. Three of these groups received their reinforcement contingent upon pressing a bar weighted at $20 \mathrm{gm}, 50 \mathrm{gm}$, and $80 \mathrm{gm}$ respectively. The fourth group received reinforcements noncontingent upon the bar press. A control group received noncontingent reinforcements of $0.1 \mathrm{cc}$ distilled water. Following training, all five groups were given a cafeteria-style preference test in which the same maltose solution, used as a reinforcer, was available along with an alternative solution of sucrose. The consumption measures indicated a linear decline in Ss' preference for the reinforcer, as a function of increased effort expenditure.

Lawrence \& Festinger (1961) have suggested that the amount of effort an animal is required to exert during training is directly related to the attractiveness of the learning situation. They originally related this attractiveness of the training situation to Ss' greater resistance to extinction. The rationale for this effect had been deduced from the theoretical implications of the theory of cognitive dissonance developed by Festinger (1957)。

Lewis (1964) reported the results of three experiments in support of dissonance theory. His method consisted of training several groups of rats to run a straight-alley maze in order to obtain a food reward while pulling variously sized weights. These effortful conditions were then related to running time, eating rate, and the amount of reward-pellets the animals consumed following $22 \mathrm{hr}$. of ad-libitum feeding. These three measures were inferred to reflect Ss' preference for the food (goal object). Lewis concluded from his results that animals expending the greatest effort in the training phase of his experiments developed the strongest "preference" for the reinforcing agent. However, preference denotes a favoring of one object over another. Lewis did not attempt to offer his Ss an alternative to the goal object and thus has not satisfied his claim to have demonstrated a greater preference for the goal object in the more "dissonant" situation.

In contrast with the previous findings, Sheridan, Levinson, \& Cristal (1965) have demonstrated that by varying the schedule of reinforcements for several groups of rats, that Ss' preference for the reinforcer would change in the direction of decreasing magnitude with an associated increment in the FR schedule. The measure of preference consisted of a cafeteria-style presentation of the reinforcing solution of maltose and a previously non-exposed solution of sucrose. The authors pointed out, that although they had found a statistically significant decrement in Ss' preference for the goal object, the source of the decrement could be due to either the effect of temporal spacing of the reinforcer, or the work requirements of the training situation.

This latter evidence, although discordant with expectations derived from dissonance theory, is quite compatible with an incentive theory. If one may think of pleasure as a decrement in the amount of effort the animal must expend in order to obtain a goal object, and the converse of pleasure an increment in the amount of effort the animal must expend, then we may think of the former situation as producing positive incentives and the latter case as producing negative incentives.

In terms of this formulation, it may be expected that increasing the amount of positive incentives associated with a task would tend to increase Ss' preference for that task, as well as elements associated with the task, i.e., the goal object.

The experiment reported here represents a further attempt to elucidate the relationship between the amount of effort an animal is required to exert in order to obtain a goal object and his subsequent preference for that goal object.

Subjects

Ss were 24 male albino rats from 90 to 120 days old at the beginning of the experiment. They were randomly assigned to four "work" groups and two "no-work" groups.

Apparafus

The training apparatus consisted of a Skinner box, $16 \times 12 \times 12$ in.(inside dimensions) with a telegraph-key bar mounted on a 5 in. piece of Plexiglas which was affixed to the $12 \times 12 \mathrm{in}$. panel. A set of metric weights was used to vary the weight of the bar. A 1 cc hypodermic syringe graduate to $1 / 20 \mathrm{cc}$, permitted accurate delivery of $0.1 \mathrm{M}$ solution of maltose which was prepared fresh daily by dissolving appropriate amounts of "Maltose, practical" (made by Matheson, Coleman, and Bell, East Rutherford, N.J.) in distilled water.

During the testing phase Ss were placed in a 12 in. square cage with two drinking bottles arranged so that the tubes were no more than $3 \mathrm{~cm}$ apart at their distal ends (from the necks of the bottles). The solution used as an alternative to test for maltose preference was $0.1 \mathrm{M}$ solution of sucrose made by dissolving an appropriate amount of cane sugar in distilled water.

\section{Procedure}

On days 1-4, all Ss were placed on a $23 \mathrm{hr}$. water deprivation schedule. The Ss were maintained on this schedule throughout the course of the experiment with 1 
hr. of watering at the conclusion of the day's training. An adequate amount of food was always available in the home cages.

On days 5-8, Ss were taken from their home cages and placed in the training cage. All Ss in the work groups were shaped to a "light" bar $(20 \mathrm{gm})$; they received 0.1 cc of maltose solution for each bar press, for a maximum of $2 \mathrm{cc} /$ day. The maltose control (MC) Ss and the water control (WC) Ss received 0.1 cc of maltose solution or distilled water, respectively, atbrief intervals so as to preclude any systematic activity. These two groups also received a maximum of $2 \mathrm{cc} / \mathrm{day}$, of their respective solutions.

On days 9-12, the bar pressing Ss were placed on their respective effort schedules: group WG-1 was maintained on the $20 \mathrm{gm}$ bar; group WG-2 was trained on the $50 \mathrm{gm}$ bar; group WG-3 was trained to press an $80 \mathrm{gm}$ bar; group WG-4 was trained to press the $110 \mathrm{gm}$ bar.

Testing for preference. On days 13-16, all Ss were placed individually, for a period of $20 \mathrm{~min}$., in the testing apparatus with two drinking bottles. Bottle A contained $100 \mathrm{cc}$ of a solution of maltose and bottle B contained $100 \mathrm{cc}$ of a solution of sucrose. The position of the two bottles was alternated, i.e., left or right side, day to day for the four consecutive days of testing for preference. At the end of the $20 \mathrm{~min}$. period $\mathrm{S}$ was returned to his home cage and watered for an additional $40 \mathrm{~min}$. The amount of liquid remaining in each of the testing bottles was measured to the nearest cc. This figure was then subtracted from $100 \mathrm{cc}$ in order to ascertain the amount of each solution consumed by the animal. Results

During the course of the experiment it was necessary to drop the $110 \mathrm{gm}$ group since members of this group did not reach the criterion of an efficient bar press (activation of electric counter). Prior to the onset of preference testing one $S$ from the $80 \mathrm{gm}$ group died and it is for this reason that the latter group had only three Ss while all other groups had four. In all other respects the experimental procedure remained intact.

The amount of maltose consumed by each animal over the four days of testing was converted into a percentage of his total liquid consumption (maltose/maltose + sucrose). The mean percentages of maltose consumed by each group exposed to maltose during training are presented in Table 1.

Table 1. Effect of differential effort expenditure on mean of $\%$ maltose consumption of the four days of testing.

\begin{tabular}{cccc}
$\begin{array}{c}\text { Group } \\
M C\end{array}$ & $\begin{array}{c}\text { Group } \\
\text { WG-1 }\end{array}$ & $\begin{array}{c}\text { Group } \\
\text { WG-2 }\end{array}$ & $\begin{array}{l}\text { Group } \\
\text { WG-3 }\end{array}$ \\
\hline 74.13 & 57.28 & 50.81 & $\ldots .42$ \\
\hline
\end{tabular}

$F$-Test $F=4.502 ; p<.05$.

F-Test (linear trend) $F=5.858: p<.05$
The mean percentage of maltose consumed by the two "no-work" groups (WC and MC) over four days of testing differed significantly ( $p<.01$, two tailed; $t$-Test), thus indicating an increased preference for maltose solution as a function of pre-test exposure and subsequent adaptation to the maltose solution.

The effect of effort expenditure on Ss'subsequent preference for the reinforcer was assessed by applying an F-Test (Edwards, 1963) in order to compare the differences between the four groups receiving maltose solution during testing ( $M C$, WG-1, WG-2, and WG-3). From this analysis, it was found that the amount of effort the animal was required to expend in order to obtain the reinforcer was differentially related to the animal's preference for the reinforcer as seen in Table $1(p<.05)$.

In order to determine whether the relationship between the effort variable and $\mathrm{Ss}^{\prime}$ preference for the reinforcer was linear, a test for linearity was performed. It was concluded from the obtained F ratios that there is a significant negative linear trend in the treatment means $(\mathrm{p}<.05)$.

\section{Discussion}

The results show that the effect of familiarization with the maltose solution is reflected in an increased preference for the reinforcer, as demonstrated in the comparison between WC and MC groups. However, this preference for the reinforcer decreases as a linear function with an increase in the amount of effort required of the S to obtain the reinforcer.

The findings of this experiment support the contention implied by Sheridan's study, that it would be fallacious to hypothesize an increment in "extra attractions" associated with the goal objectas a result of Ss' increased effort expenditure; and that an increase in these "extra attractions," if any, would have to be associated with something other than the goal object. In fact, the present results suggest that increased effort expenditure decreases the attractiveness of the goal object.

The explanation offered by an incentive theory seems to offer, at least, a tentative means of dealing with the present findings.

\section{References}

Edwards, A. L. Experimental design in psychological research. New York: Holt, Rinehart and Winston, 1963.

Festinger, L. A theory of cognitive dissonance. Evanston, Ill.: Row, Peterc sn, i357.

Lawrence, D H., \& Festinger, L. Deterrents and reinforcements. Stanford, Calif.: Stanford Press, 1962.

Lewis, M. Some nondecremental effects of effort. J. comp. physiol. Psychol., 1964, 57, 367-372.

Sheridan, C. L., Levinson, D. M., \& Cristal, R. M. Effects of fixed ratio training on subsequent preference for the reinforcer. Psychon. Sci., 1965, 2, 263-264.

Note

1. The writer wishes to thank Dr. John A. Ceraso for his helpful suggestions. 